\title{
MEIOTIC CHROMOSOME PAIRING IN TWO INTERSPECIFIC HYBRIDS AND A CRITICISM OF THE EVOLUTIONARY RELATIONSHIP OF DIPLOID AVENA
}

\author{
ICHIZO NISHIYAMA ${ }^{1)}$ AND TOMOSABURO YABUNO \\ Faculty of Agriculture, Meijo University, Nagoya 468 \\ and College of Agriculture, University \\ of Osaka Prefecture, Osaka 591
}

Received August 11, 1975

In recent years the authors have obtained many interspecific hybrids of Avena during a study of a mechanism of cross-incompatibility, especially due to endospermic abortion of seeds. Some of them were cytologically studied (Yabuno and Nishiyama (1975). This paper deals with meiotic chromosome behavior of two diploid hybrids, $A$. pilosa crossed with $A$. strigosa and $A$. ventricosa. The former is a new hybrid which is obtained only when $A$. pilosa is used as a male parent. The cytological investigation has revealed the poor relationship between $A$. strigosa and $A$. pilos $a$ as presumed by Thomas and Rajhathy (1967). Based on the available cytogenetic information the phylogenetic relationships among diploid species of Avena are discussed.

\section{MATERIALS AND METHODS}

Two diploid hybrids, Avena strigosa $\times$ A. pilosa and A. pilosa $\times$ A. ventricosa, have been cytologically studied. The former was successful when $A$. strigosa was crossed with $A$. pilosa pollen although crossed seeds poorly developed. The reciprocal hybridization gave non-viable empty and shrivelled seeds at maturity. Reciprocal crosses were successfully made between $A$. pilosa and $A$. ventricosa. Seed germination was tried in petri dishes under temperature of $20^{\circ} \pm 0.5^{\circ} \mathrm{C}$, and potted plants were mostly grown in the green house. In the meiotic observation of PMC's material was fixed in Carnoy's solution $(6: 3: 1)$, stored in $70 \%$ alcohol and stained in aceto-carmine. Slide preparation was made by the squash method.

\section{RESULTS}

Morphological observation: Morphological characteristics of the hybrid A. strigosa $\times$ A. pilosa and its parents are briefly summarized in Table 1. It is generally said that most of $A$. pilosa characteristics (weed type) are dominant over the cultivated type of A. strigosa but a few intermediate. Pubescence of leaf blades and sheaths was ob-

1) Present address: 18 Hazamacho, Shugakuin, Sakyo-ku, Kyoto 606. 
Table 1. Morphology of A. strigosa, A. pilosa and their hybrid

\begin{tabular}{|c|c|c|c|}
\hline Characteristics & A. strigosa & A. pilosa & Hybrid \\
\hline Juvenile growth habit & Erect & Prostrate & Semi-prostrate \\
\hline \multicolumn{4}{|l|}{ Hairs on leaf blades } \\
\hline Upper surface & Glabrous & Glabrous & Glabrous \\
\hline Under surface & Glabrous & Slightly hairy & Slightly hairy \\
\hline Leaf margins & Glabrous & Ciliate & Ciliate \\
\hline Hairs on sheaths & Glabrous & Slightly hairy & Slightly hairy \\
\hline Time of anthesis & About 7:00 p.m. & About 4:30 p.m. & About 5:30 p.m. \\
\hline Spikelet type & Cultivated type & Semi-wild type & Semi-wild type \\
\hline \multicolumn{4}{|l|}{ Hairs on lemma } \\
\hline Upper part & Glabrous & Short, fine hairs & Short, fine hairs \\
\hline Hairs of scar and rachilla & Glabrous & Densely hairy & Densely hairy \\
\hline Hairs of awn (twisted part) & Glabrous & Short, fine hairs & Short, fine hairs \\
\hline Ratio of empty glume length & $1: 1.19$ & $1: 1.90$ & $1: 1.36$ \\
\hline
\end{tabular}

served in a young stage of the hybrid, but might be easily removed in mid to adult stages.

Time of daily anthesis of $A$. strigosa and $A$. pilosa was observed to be around 7:00 p.m. and 4:30 p.m., respectively, under regular weather condition (Nishiyama 1970). The $\mathrm{F}_{1}$ hybrid showed intermediate, about 5:30 p.m., being rather close to an early flowering parent. A. strigosa indicates nonshattering of spikelets and florets at maturity. A. pilosa is of a typical semi-wild-type separation, that is, the spikelet easily separates from its pedicel by abscission leaving a long narrow basal scar but the florets remain attached together. The semi-wild type is completely dominant in the hybrid and the basal scar is long rounded to eliptic cavity, being similar to that of $A$. barbata. First and second empty glumes of $A$. strigosa are approximately equal in length, 1:1.19, while $A$. pilosa indicates unequal length, 1:1.90. The $\mathrm{F}_{1}$ hybrid expressed an intermediate ratio $1: 1.36$, or rather close to the equal glume type.

A. ventricosa is morphologically similar to $A$. pilosa, except a few characteristics. In their hybrid the equal glume type, 1:1.24, of $A$. ventricosa was almost completely dominant. A. ventricosa is especially characterized by a very elongated grain-base with very sharp, pointed narrow scar. The basal scar of the $F_{1}$ hybrid was almost similar to that of $A$. pilosa.

Both of the two interspecific hybrids were highly sterile, only three seeds being found in $A$. strigosa $\times A$. pilosa under free pollination. Of them one germinated but died in a seedling stage.

Chromosome observation: Very poor pairing of chromosomes was observed at metaphase I of PMC's in A. strigosa $\times A$. pilosa. A total of 256 PMC's indicates $0-4$ bivalents, with a mean number of 0.75 bivalents per cell (Table 2). All bivalents were of rod shape. No complex association of chromosomes was observed.

The $\mathrm{F}_{1}$ hybrid $A$. pilosa $\times A$. ventricosa is characterized by irregular pairing of chromosomes at metaphase I. Although seven bivalents were found in an extreme 
Table 2. Chromosome pairing of a hybrid, A. strigosa $\times$ A. pilosa

\begin{tabular}{c|c}
\hline \hline Chromosome configuration & Frequency \\
\hline $4_{\text {II }}+6_{\text {I }}$ & 3 \\
$3_{\text {II }}+8_{\text {I }}$ & 11 \\
$2_{\text {II }}+10_{\text {I }}$ & 35 \\
$1_{\text {II }}+12_{\text {I }}$ & 78 \\
$14_{\text {I }}$ & 129 \\
\hline Total & 256 \\
Mean 0.75 per cell & \\
\hline
\end{tabular}

case, chromosome configurations usually consisted of some univalents, bivalents and complexes of $3-5$ chromosomes. $1_{\text {II }}+4_{\text {II }}+3_{\text {I }}$ or $1_{\text {III }}+3_{\text {II }}+5_{\text {I }}$ were most frequently observed (Table 3 ). Most of bivalents were of rod shape, ring shaped pairs being only 0-2 per cell. When associations of 3,4 , and 5 chromosomes are treated as 1,2 and 2 bivalents, respectively, the revised number of bivalents ranges $3-7$, with a mean

Table 3. Chromosome pairing of a hybrid,

$A$. pilosa $\times A$. ventricosa

\begin{tabular}{|c|c|c|c|c|c|c|c|}
\hline \multicolumn{7}{|c|}{ Chromosome configuration } & \multirow{2}{*}{$\frac{\text { Frequency }}{1}$} \\
\hline & & & & & $7_{\text {II }}$ & & \\
\hline & & $1_{\mathrm{IV}}$ & & + & $4_{\text {II }}+$ & $2_{\text {I }}$ & 2 \\
\hline & & & $1_{\mathrm{III}}$ & + & $5_{\text {II }}+$ & $1_{I}$ & 4 \\
\hline & & & & & 6 II + & $2_{I}$ & 8 \\
\hline \multirow[t]{17}{*}{$1_{\mathrm{V}}$} & + & $1_{\mathrm{IV}}$ & & + & $1_{\text {II }}+$ & $3_{\text {I }}$ & 1 \\
\hline & & $1_{\mathrm{IV}}+$ & $1_{\text {III }}$ & + & $2_{\text {II }}+$ & $3_{\text {I }}$ & 1 \\
\hline & & $1_{\mathrm{IV}}$ & & + & $3_{\text {II }}+$ & $4_{I}$ & 1 \\
\hline & & & $3_{\text {III }}$ & + & $2_{\mathrm{II}}+$ & $1_{I}$ & 1 \\
\hline & & & $2_{\mathrm{III}}$ & + & $3_{\text {II }}+$ & $2_{\text {I }}$ & 7 \\
\hline & & & $1_{\text {III }}$ & + & $4_{\text {II }}+$ & $3_{\text {I }}$ & 11 \\
\hline & & & & & $5_{\text {II }}+$ & $4_{\mathrm{I}}$ & 6 \\
\hline & & $1_{\mathrm{IV}}+$ & $1_{\text {III }}$ & + & $1_{\text {II }}+$ & $5_{\text {I }}$ & 1 \\
\hline & & $1_{\mathrm{IV}}+$ & $2_{\mathrm{III}}$ & & + & $4_{I}$ & 1 \\
\hline & & & $3_{\text {III }}$ & + & $1_{\text {II }}+$ & $3_{\text {I }}$ & 3 \\
\hline & & & $2_{\text {III }}$ & + & $2_{\text {II }}+$ & $4_{\mathrm{I}}$ & 7 \\
\hline & & & $1_{\text {III }}$ & + & $3_{\text {II }}+$ & $5_{1}$ & 11 \\
\hline & & & & & $4_{\text {II }}+$ & $66_{\mathrm{I}}$ & 2 \\
\hline & & & $2_{\text {III }}$ & + & $1_{\text {II }}+$ & $6_{\text {I }}$ & 1 \\
\hline & & & & + & $2_{\text {II }}+$ & $7_{\mathrm{I}}$ & 2 \\
\hline & & & & & $3_{\text {II }}+$ & $8_{I}$ & 1 \\
\hline & & Mean 4 & $\begin{array}{l}\text { Tota } \\
78_{\text {II }}\end{array}$ & 1 & cell & & 72 \\
\hline
\end{tabular}


number of 4.78 bivalents per cell.

\section{DISCUSSION}

The hybrid $A$. strigosa $\times A$. pilosa indicated 0-4 bivalents with a mean number of 0.75 bivalents at metaphase I. It accords an estimated number of bivalents, 0.89 , between $A$. hirtula and $A$. pilosa from the data found in the hybrid between two amphiploids, A. pilosa-sativa and $A$. hirtula-sativa (Thomas and Rajhathy 1967). Complex configurations consisting of uni-, bi-, tri- and quadrivalents were usually found in A. pilosa $\times A$. ventricosa. The revised mean number of bivalents amounts to 4.78 per cell. This result is in fairly well agreement with extensive observations of Rajhathy and Thomas (1967), showing 4.35 to 5.04 bivalents per cell.

Based on the raw data of chromosome configurations in Tables 2 and 3 genome relationships between the three diploid species are tentatively illustrated in Fig. 1. It is presumed that $A$. strigosa has a standard genome consisting of 7 chromosomes numbered on both ends. Four $A$. pilosa chromosomes are partially homologous to those of $A$. strigosa, but the remainder has differentiated to $A$. pilosa proper.

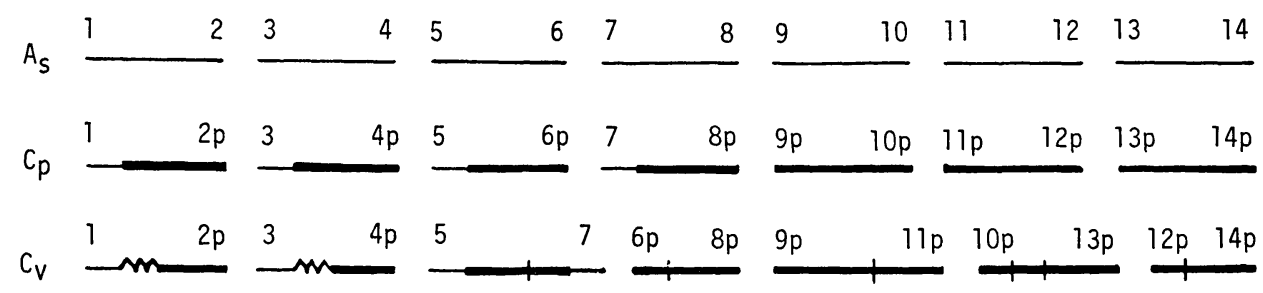

Fig. 1. Diagrams showing structural divergences between three genomes, As, Cp and $\mathrm{Cv}$. As (tentative standard type): $A$. strigosa, $\mathrm{Cp}: A$. pilosa, $\mathrm{Cv}: A$. ventricosa.

Three chromosome interchanges may be enough to explain meiotic pairing in $A$. pilosa $\times A$. ventricosa. Rare occurrence of 1-2 ring shaped bivalents is suggestive that their partners also are partially nonhomologous, probably in interstitial segments as illustrated in two pairs from the left in Fig. 1. In short, on the basis of meiotic chromosome behavior of the hybrids it is confirmed that $A$. pilosa is obviously closer to $A$. ventricosa than $A$. strigosa. Of course, $A$. ventricosa also appears to relate poorly to $A$. strigosa.

Since establishment of the genus Avena by Tournefort in 1700 there have been several opinions on the origin and classification of the species (see Coffman 1961). On the morphological grounds Malzew (1930) reported comprehensive investigation on the phylogenetic relatonship of the section Euavena. In a recent decade the genus including newly discovered species was extensively studied by many authors from stand points of karyotype, genome affinity, morphology, cross-compatibility, and geographical distribution. Reflecting all information now available Rajhathy and Thomas (1974) reexamined the phylogenetic situation of Avena and revised Malzew's evolutionary 
sequence, especially in three problems as follows:

(1) All of seven diploid biological species were classified into two groups with AA and $\mathrm{CC}$ genomes. The latter has $A$. pilosa (Cp $\mathrm{Cp}$ genomes) and $A$. ventricosa $(\mathrm{Cv} \mathrm{Cv})$, and the former includes the remainder, A. strigosa (As As), A. longiglumis (Al Al), A. damascena (Ad Ad), A. prostrata (Ap Ap) and A. canariensis (Ac Ac).

(2) A. barbata (AABB), including $A$. vaviloviana and $A$. abyssinica, is a biological species but not a tetraploid donor to the hexaploid species.

(3) A. murphyi has AACC genomes and is a tetraploid ancestor of hexaploids (AACCDD).

At present there are still several opinions on the relationship of diploid oats, especially in the AA genome group. Based on evidence from cytogenetics and morphology Holden (1966) suggested that A. strigosa did not arise from $A$. longiglumis and that both were probably diverging lines from a common ancestor. Ladizinsky (1971, 1973) who discovered a new diploid $A$. prostrata mentioned that the new species could be regarded a more ancient type from which evolution proceeded in two different pathways, (1) A. longiglumis and (2) A. strigosa and A. damascena. From stand points of karyotype evolution and structural divergence of chromosomes Rajhathy and his coworkers finally concluded that the $\mathrm{Ap} \rightarrow \mathrm{Al} \rightarrow \mathrm{Ad} \rightarrow \mathrm{Ac} \rightarrow$ As sequence is most probable (Rajhathy and Morrison 1959, 1960, Rajhathy and Baum 1972, Rajhathy and Thomas 1974).

The ploidy status of Avena should be discussed on the grounds of three basic evolutionary mechanisms, i.e. (1) structural divergence of chromosomes, (2) formation of ploidy, and (3) genetic differentiation with no or a few minor structural changes of chromosomes which appear to promote speciation of Avena. Either of these or strictly speaking a combination of them might actually result in the differentiation of species.

The present paper, however, deals with a further criticism of a phylogenetic development of diploid species. Diploid Avena appears to be classified into three groups having unique genetic systems under which speciation took place. Five well known diploids, A. hirtula, A. wiestii, A. strigosa, A. brevis, and A. nudibrevis, can be grouped into the same category. They show a wide differentiation of plant morphology from wild to naked type, and all of them have the same genomes AsAs, characterized by almost no structural difference of chromosomes. They are completely interfertile. Then we trend to a speculative assumption that the karyotype of this group is unchangeable and remains at the primitive type or is close to it. It is probably most striking to find a similar successful evolution of cultivated barley.

On the basis of cytological evidence presented by several authors it appears that genomes of the four species, A. longiglumis, A. prostrata, A. damascena and A. canariensis, still retain high pairing affinity to that of $A$. strigosa, although tolerably diverged in chromosome structure. For instance, $A$. prostrata $\times A$. strigosa indicated $3_{\text {III }}+1_{\mathrm{V}}$ most frequently (Ladizinsky 1973). On the other hand, some of them were hardly crossed with AsAs species and highly sterile when hybridized. Thus their genomes are distinctly distinguished from the $\mathrm{A}$ (or As) genome, and should be deservingly designated as ${ }^{\mathrm{T}} \mathrm{A}$. Interspecific hybrids within ${ }^{\mathrm{T}} \mathrm{A}^{\mathrm{T}} \mathrm{A}$ genome group were sterile and indicated some structural divergences between parent genomes. Then $A$. 
longiglumis, A. prostrata, A. damascena and $A$. canariensis should be designated as modified symbols such as ${ }^{\mathrm{T}} \mathrm{Al},{ }^{\mathrm{T}} \mathrm{Ap},{ }^{\mathrm{T}} \mathrm{Ad}$, and ${ }^{\mathrm{T}} \mathrm{Ac}$, respectively. Accordingly further details of relative genomic homology may be demonstrated with the number of bivalents, except associations of three or more chromosomes, in their hybrids. The following scheme shows mean frequencies of bivalents per cell in interspecific hybrids which were cited from Table 3 in an article of Rajhathy and Thomas (1974). It is clear that As relates poorly to ${ }^{\mathrm{T}} \mathrm{Ap}$ and ${ }^{\mathrm{T}} \mathrm{Al}$, both of which have the closest relationship, and ${ }^{\mathrm{T}} \mathrm{Ap}$ resembles ${ }^{\mathrm{T}} \mathrm{Ac}$ and ${ }^{\mathrm{T}} \mathrm{Ad}$ closely. According to Ladizinsky (1971, 1973), Rajhathy and Baum (1972), Rajhathy and Thomas (1974) and Craig, Murray and Rajhathy (1974) the morphology of $A$. prostrata, A. damascena and $A$. canariensis are very similar to that of $A$. wiestii or $A$. hirtula which are of the most primitive type in the AsAs group. These results tend to support a notion that the genetic system of all species in the ${ }^{\mathrm{T}} \mathrm{A}^{\mathrm{T}} \mathrm{A}$ group, except $A$. longiglumis, showed a frequent occurrence of chromosome structural changes but a few or no morphological divergence. In other words it means that the ${ }^{\mathrm{T}} \mathrm{A}^{\mathrm{T}} \mathrm{A}$ group, especially $A$. prostrata maintains the primitive type in most of plant characteristics but hardly of the karyotype.

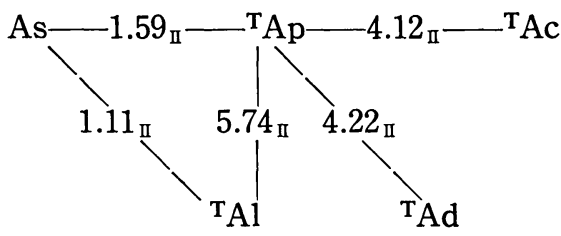

Comparative demonstration of karyotypes in Avena was briefly summarized by Rajhathy and Thomas (1974). Based on the data the karyotype similarity in the As As and ${ }^{\mathrm{T}} \mathrm{A}^{\mathrm{T}} \mathrm{A}$ groups can be roughly shown as follows when As is tentatively a standard type.

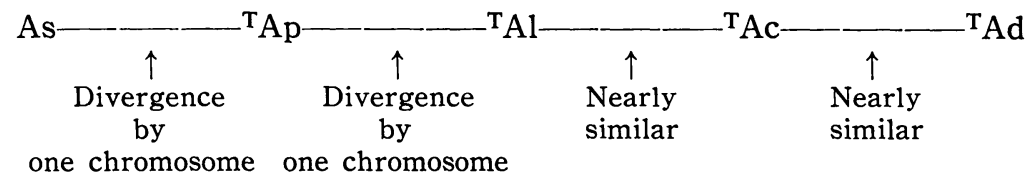

The karyotype sequence accords closely with the chromosome affinity relationship mentioned above. As suggested by previous authors, however, a general concept of karyotype evolution appears to be hardly applied to these karyotypes.

A. longiglumis might evolve from $A$. prostrata and progress toward a remarkable specialization with some unique characteristics, e.g. daily anthesis about 4:00 a.m., formation of giant anthers, strong activity for initiating mitosis of fertilized polar nuclei, growth habit, especially almost full-elongation of the peduncle before beginning of anthesis in the spike (Yabuno and Nishiyama 1975).

The karyotype and genome of $A$. pilosa including $A$. clauda, and $A$. ventricosa were designated as $\mathrm{Cp}$ and $\mathrm{Cv}$, respectively (Rajhathy 1966, Rajhathy and Dyck 1963, Thomas and Rajhathy 1967, Rajhathy and Thomas 1974). Difficulty of interspecific 
crossing or a few meiotic pairs in $\mathrm{F}_{1}$ hybrids suggest a very poor relationship between the CC group and ${ }^{\mathrm{T}} \mathrm{A}^{\mathrm{T}} \mathrm{A}$ as well as AsAs groups (Rajhathy and Dyck 1963, Rajhathy and Thomas 1967, 1974, present study). The establishment of the $\mathrm{C}$ genome might be due to accumulation of rather small segmental rearrangements of chromosomes, probably associated with differentiation of some morphological and physiological characters. Spikelets or florets of the CC group, especially of $A$. ventricosa, indicate very elongated sharp, pointed base with narrow small scars. The base type is more effective for penetration of grains into ground. It is interesting to note that $A$. pilosa crossed with $A$. strigosa showed elongated elliptical scars, similar to those of $A$.

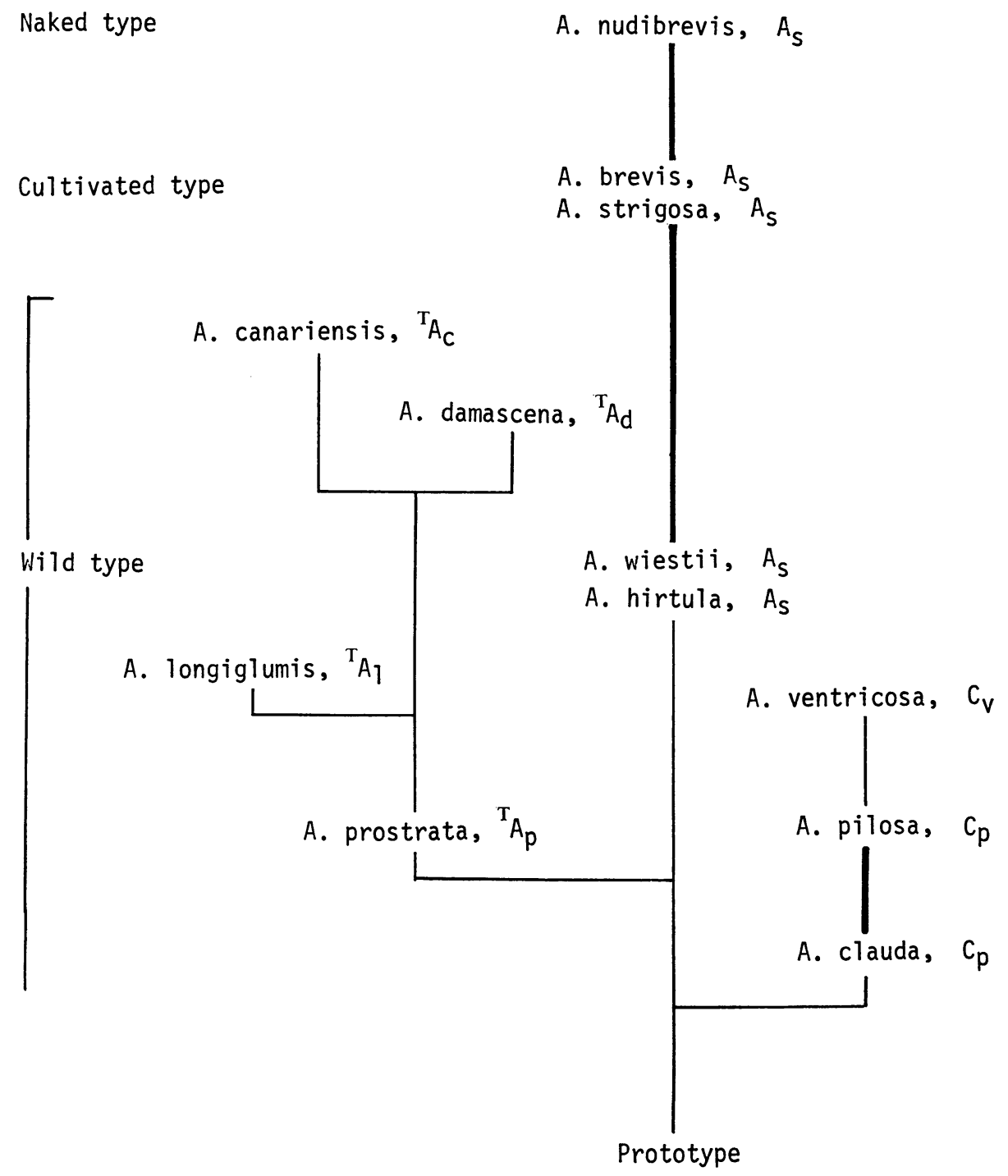

Fig. 2. A tentative genealogical tree of diploid Avena. Thick line indicates the same genome constitution. 
barbata. It seems that the $\mathrm{CC}$ group has made progressive speciation toward the superwild type of base. The same may be true in A. longiglumis, showing the same base type as $A$. pilosa.

In short, based on our understanding cytogenetic data Fig. 2 illustrates a tentative evolutionary sequence of diploid species in Avena. It appears to be supported by evidence from plant morphology, cross-compatibility, geographical and ecological distribution (Ladizinsky 1971, 1973, Ladizinsky and Zohary 1971, Rajhathy and Thomas 1974).

Rajhathy and Thomas (1974) have preliminarily given an interesting summary of the ploidy evolution of tetraploid and hexaploid species. As cytogenetic evidence for this concept is still insufficient it is difficult to make a further discussion on this problem.

\section{SUMMARY}

A new cross, A. strigosa $\times A$. pilosa, was successfully made when $A$. pilosa was a pollen parent. The hybrid indicated $0-4$ bivalents with an average 0.75 bivalents per cell.

In $A$. pilos $\times \times A$. ventricosa chromosome configurations of $1_{\mathrm{III}}+4_{\mathrm{II}}+3_{\mathrm{I}}$ and $1_{\mathrm{II}}+$ $3_{\text {II }}+5_{\text {I }}$ were most frequentry observed although they usually varied widely.

Based on the available cytogenetic evidence the authors arranged all diploid oats in three groups with AsAs (or $\mathrm{AA}$ ), ${ }^{\mathrm{T}} \mathrm{A}^{\mathrm{T}} \mathrm{A}$ and $\mathrm{CC}$ genomes. They might have a common ancestor and make progress in different trends of their unique specialization.

\section{LITERATURE CITED}

Coffman, F. A., 1961 Origin and history: in Ed. by Coffman. Oats and oat improvement. Amer. Soc. Agronomy, Madison, Wis. USA: 15-40.

Craig, I. L., B. E. Murray, and T. Rajhathy, 1974 Morphological and electrophoretic polymorphism and relationship to the A. magna-A. murphyi complex and A. sterilis. Can. J. Genet. Cytol. 16: 677-689.

Holden, J. H. W., 1966 Species relationships in the Avenae. Chromosoma (Berl.) 20: 75-124.

Ladizinsky, G., 1971 Avena prostrata: A new diploid species of oat. Israel J. Bot. 20: 297-301.

Ladizinsky, G., 1973 The cytogenetic position of Avena prostrata among the diploid oats. Can. J. Genet. Cytol. 15: 443-450.

Ladizinsky, G., and D. Zohary, 1971 Notes on species delimitation, species relationships and polyploidy in Avena L. Euphytica 20: 380-395.

Malzew, A. T., 1930 Wild and cultivated oats (Section Euavena Griseb.). Bull. Appl. Botany, Genetics and Plant Breeding, Leningrad, Suppl. 38.

Nishiyama, I., 1970 Four types of flowering time in Avena. Japan. J. Genetics 45: 399-409.

Rajhathy, T., 1961 Chromosomal differentiation and speciation in diploid Avena. Can. J. Genet. Cytol. 3: 372-377.

Rajhathy, T., 1966 Evidence and a hypothesis for the origin of the $\mathrm{C}$ genome of hexaploid Avena. Can. J. Genet. Cytol. 8: 774-779.

Rajhathy, T., and J. W. Morrison, 1959 Chromosome morphology in the genus Avena. Can. J. Botany 37: 331-337.

Rajhathy, T., and J. W. Morrison, 1960 Genome homology in the genus Avena. Can. J. Genet. Cytol. 2: 278-285. 
Rajhathy, T., and P. L. Dyck, 1963 Chromosomal differentiation and speciation in diploid Avena. II. The karyotype of A. pilosa. Can. J. Genet. Cytol. 5: 175-179.

Rajhathy, T., and H. Thomas, 1967 Chromosomal differentiation and speciation in diploid Avena. III. Mediterranean wild populations. Can. J. Genet. Cytol. 9: 52-68.

Rajhathy, T., and B. R. Baum, 1972 Avena damascena: A new diploid oat species. Can. J. Genet. Cytol. 14: 645-654.

Rajhathy, T., and H. Thomas, 1974 Cytogenetics of oats (Avena L.). Miscel. Pub. Genet. Soc. Canada No. 2: 1-90.

Thomas, H., 1970 Chromosome relationship between the cultivated oat Avena sativa (6x) and A. ventricosa $(2 \mathrm{x})$. Can. J. Genet. Cytol. 12: 36-43.

Thomas, H., and M. Lloyed-Jones, 1965 Chromosomal differentiation in diploid species of Avena. Can. J. Genet. Cytol. 7: 108-111.

Thomas, H., and T. Rajhathy, 1967 Chromosome relationships between Avena sativa (6x) and Avena pilosa (2x). Can. J. Genet. Cytol. 9: 154-162.

Yabuno, T., and I. Nishiyama, 1975 Chromosome relationships in interspecific Avena hybrids, with special reference to hybrids with A. longiglumis. Japan. J. Genetics 50: 329-339. 